far, a timely reminder of how much more work there is to be done in the general field of inorganic preparative chemistry. The articles on fluorides are of great significance; that on binary fluorides deals at length with the general features of fluorinating agents, with a well informed critical discussion of the reagents currently employed in this type of work, while that on the fluorine compounds of the platinum metals brings together a large number of previously unconnected preparative methods in a particularly difficult part of chemistry.

This book is a worthwhile addition to the chemical literature. An adequate subject and author index is included, together with a cumulative index for Volumes 1 and 2 .

D. S. PAYNE

\section{PROTOZOOLOGY PATCHED UP}

\section{Protozoology}

By Richard R. Kudo. Fifth edition. Pp. $x i+1174$. (Springfield, Ill.: Charles C. Thomas, 1966.) \$15.75.

The fifth edition of Kudo's Protozoology elosely follows the fourth in general arrangement and content. There are now almost 300 pages of general biology, followed by more than 750 pages of taxonomy. The increase is due mainly to a larger print, although there has been an injection of new material here and there. The book is well produced and convenient to use.

It remains exceedingly useful to have such a large selection of the genera of the Protozoa described systematically, with many good line drawings, and this section of the book is acceptable and valuable. The "Opalinida", formerly "Protociliata", are officially dismissed from the ciliates, but find themselves uncomfortably included at the end of the chapter on peritrichs; and the Suctoria surprisingly retain the status of a class.

The section on general biology is largely out of date and needs rewriting rather than the patching which it has received. Notwithstanding the immense contribution which medical protozoology has made to human welfare, Protozoa are now also playing an important part in the study of cell biology, and the study of parasitic Protozoa can only benefit from a recognition of the cell-biological aspect of protozoology. The first chapter contains a history of protozoology in which electron microscopy is not mentioned.

The revolution in protozoology produced by the electron microscope has indeed made little impression on this book. The structure of cilia and flagella, of parabasal bodies, of the cell surface, of the cortex of ciliates, of fibrillar systems and myonemes, and of the surface of the nucleus, is treated in a manner which is out of date. Old drawings should be replaced by diagrams based on modern electron microscopy.

The physiology of Protozoa suffers from being treated in a separate chapter, divorced from morphology; I think that it is more fruitful to deal with functional systems as such. As it is, interesting modern developments and problems are neglected in the discussion of various forms of protoplasmic movements. Mitochondria also fare badly, with a brief reference to the view that they may have something to do with the cell respiration. Morphogenesis is passed over, and regeneration (in the chapter on reproduction) is treated excoedingly briefly, with poor selection of material and virtually no discussion of all that is interesting and exciting in the regeneration of Stentor and Euplotes.

A chapter on ecology describes the range of conditions which Protozoa can survivo, but gives little impression of the real scope of this subject. In the chapter on variation and heredity, the account of the genetics of Chlamydomonas has appropriately been curtailed and that of Paramecium somewhat expanded. Important observations on nuclear grafting are not described.
There is a real need for this book. Nevertheless, I suggest that those who will make good use of the taxonomic section deserve the support of a new and modern introduction. J. A. KITChING

\section{SOME RUSSIAN FRESHWATER FISHES \\ Freshwater Fishes of the U.S.S.R. and Adjacent Coun- tries}

Vol. 3. By L. S. Berg. Translated from the Russian. Fourth edition. Pp. 510. (Jerusalem: Israel Program for Scientific Translations; London: Oldbourne Press, 1965.) $108 s$.

Leo Semenovitch Berg (1876-1950) is remembered as a distinguished Russian ichthyologist and geographer of both pre-Revolutionary and Soviet eras. His treatise on the freshwater fishes of Russia and neighbouring countries first appeared in 1916, with revisions in 1923, 1932-33, and finally in 1948-49. This last edition has now appeared in English translation. The work is designed as a systematic guide to the fishes in the river basins of eastern Europe and northern Asia, so that its scope includes almost the entire Palaearetic region, including the Caspian Sea and Lake Baikal. This continental ichthyofauna has far fewer species than that of the corresponding Nearctic areas of North America, but receives an infusion of more exotic Sino-Indian forms in the Manchurian (or Amur) transitional region, included in this survey. An assemblage of 375 species, spread over the three volumes of the fourth edition, is brought to order under Berg's own classification of fishes, which, for better or worse, has come to be widely used throughout the world. The presentation of individual species follows a sequence now traditional in Russian ichthyological works of a faunistic nature. Brief descriptions and keys, with almost every species illustrated, are accompanied by data on life-history, diet, and distribution.

The first two volumes of Berg's trilogy deal in this fashion largely with the many salmonoid and cyprinoid fishes of the U.S.S.R. The present volume embraces a much more varied assortment of higher teleosts (122 species) belonging to many orders from the Anguilliformes to the Tetrodontiformes. The systematic part is dominated by members of the Baikalian and Ponto-Caspian faunal complexes-of more or less remote marine origin-which paradoxically form characteristic components of the Russian freshwater fish fauna. Now threatened by industrial pollution, Lake Baikal, the deepest and oldest freshwater basin in the world, and one famous for a high degree of endemicity among invertebrate groups, also contains two families of cottid fish (Cottocomephoridae and Comephoridae) peculiar to its waters. In the first of these groups, Berg recognizes no fewer than eight genera and sixteen species. The second family contains but a single genus, Comephorus, with two species, which are aberrant viviparous forms inhabiting depths to more than $1,000 \mathrm{~m}$; appropriately, C. dybowskii is depicted against a background of abyssal darkness. Ponto-Caspian fishes, originating from the brackish Sarmatic Sea of midMiocene times, are represented here chiefly by the Gobiidae. All the endemic gobies of the Caspian Sea are considered as well as more lacustrine species of Black Sea and Caspian drainage area. The eleven genera presented range from the generalized Neogobius to Benthophilus, comprising the grotesque and spinulose "tadpole-gobies". Even faced with such bizarre animals, howevor, more familiar freshwater fishes, such as the eel, turbot, perches and bullheads, receive considerable attention, along with glacial relict populations of Myoxocephalus quadricornis, and the various sticklebacks. Another feature of the present volume is that many euryhaline fishes of typical marine groups are incorporated by virtue of penetration into the lower reaches of rivers. In this context, grey- 